\title{
Carotid Body Tumor With Malignant Behavior in a Patient in His Eighth Decade
}

\author{
Waleed Alia, c, Kingsley Okoroafor ${ }^{\mathrm{a}}$, Ali Husain ${ }^{\mathrm{b}}$
}

\begin{abstract}
Carotid body tumors (CBTs) are rare neoplasms with rare malignant potential. These tumors are usually parasympathetic ganglia-derived lesions which located in the neck at the bifurcation of the external and internal carotid arteries. In contrary to sympathetic-derived tumors, they are often non-secretory. However, about $5 \%$ of these tumors may still secrete some of the catecholamine-related compounds. Most of these lesions are diagnosed in the third to fifth decades of life, with more cases revealed during autopsy examinations. Although it is considered a disease of middle age, elderly people are not immune. We report a case of an elderly patient in his eighth decade, who presented with a mass-like lesion in the right side of his neck during routine medical examination. Imaging study showed an enhancing mass in the carotid artery bifurcation with pressure effect and lymphadenopathy. The patient underwent surgery and tumor was removed uneventfully. The pathology report later confirmed ovalshaped cells with positive neuroendocrine markers consistent with carotid body paraganglioma. We believe these tumors are overlooked and yet may be missed without proper medical examination. We report this case for two reasons, being a very rare tumor with malignant potential in an elderly patient and to raise the awareness among medical practitioners.
\end{abstract}

Keywords: Carotid body tumor; Paragangilioma; Shamblin; Common carotid artery

\section{Introduction}

The description of these tumors in the literature goes back to almost 100 years, with the earliest successful carotid body tumor (CBT) surgery reported in 1903 [1]. Together with other

Manuscript submitted September 5, 2017, accepted September 13, 2017

aDepartment of Medicine-Cardiology, Cape Fear Valley Medical Center, Campbell University, Fayetteville, NC, USA

bDepartment of Cardiovascular Surgery, Cape Fear Valley Medical Center, Campbell University, Fayetteville, NC, USA

${ }^{\mathrm{c} C o r r e s p o n d i n g ~ A u t h o r: ~ W a l e e d ~ A l i, ~ D e p a r t m e n t ~ o f ~ M e d i c i n e-C a r d i o l o g y, ~}$ Cape Fear Valley Medical Center, Campbell University, 1638 Owen Drive, Fayetteville, NC 28304, USA. Email: waleeed197897@yahoo.com

doi: https://doi.org/10.14740/jmc2906w ganglia-derived growths, all are known as paragangilioma tumors. The true incidence of CBTs is largely unknown and many such tumors or paragangiliomas may remain either not diagnosed during life or not reported in literature [2]. Luckily, the majority of these tumors are benign. Nevertheless, malignant paragangiliomas in general are estimated with an incidence of 93 cases per 400 million persons in the United States [3]. We report a case of CBT with metastatic and malignant behavior in an elderly patient in his eighth decade, raising the question whether these tumors are very slow-growing malignant lesions rather than benign in nature.

\section{Case Report}

A 75-year-old Caucasian male presented to our facility clinic for regular check-up. Past medical history was significant for coronary artery disease status post stent placement in 2011, mild left ventricular (LV) dysfunction, hypertension and atrial fibrillation. He denied smoking, alcohol or recreational drugs. Family history was unremarkable for cancer or similar presentation. On physical examination, he was afebrile with blood pressure of 130/87 $\mathrm{mm} \mathrm{Hg}$, pulse rate of 90/min irregular, and respiratory rate of $18 / \mathrm{min}$. His neck exam revealed a welldefined painless swelling along the anterior border of the right sternocleidomastoid muscle. It was measuring around 3 $\times 2 \mathrm{~cm}$ with no palpable pulse or thrill. His routine laboratory exam was unremarkable. Carotid Doppler ultrasound was performed which was concerned for carotid bulb tumor. Subsequently, patient had computed tomography (CT) angiography of the neck. An enhancing mass was noted in the carotid artery bifurcation with mass effect on the adjacent vascular structures and airway (Figs. 1 and 2). Submandibular lymph nodes were seen. However, patient remained asymptomatic. $\mathrm{CT}$ of the abdomen and pelvis was unremarkable. Patient was admitted and vascular surgery was consulted. Plasma and 24-h urine collection were negative for catecholamine-related compounds. After discussion and surgical consent, the tumor was explored (Fig. 3). Laborious dissection around the common carotid artery was achieved with significant hemostasis. The external carotid artery had to be ligated because of significant bleeding from the branches of the artery, while the internal carotid artery was dissected and preserved. The tumor was then removed uneventfully. Patient recovered well and was discharged home in stable condition. Pathology report revealed a circumscribed tumor with fibrous bands and dilated 

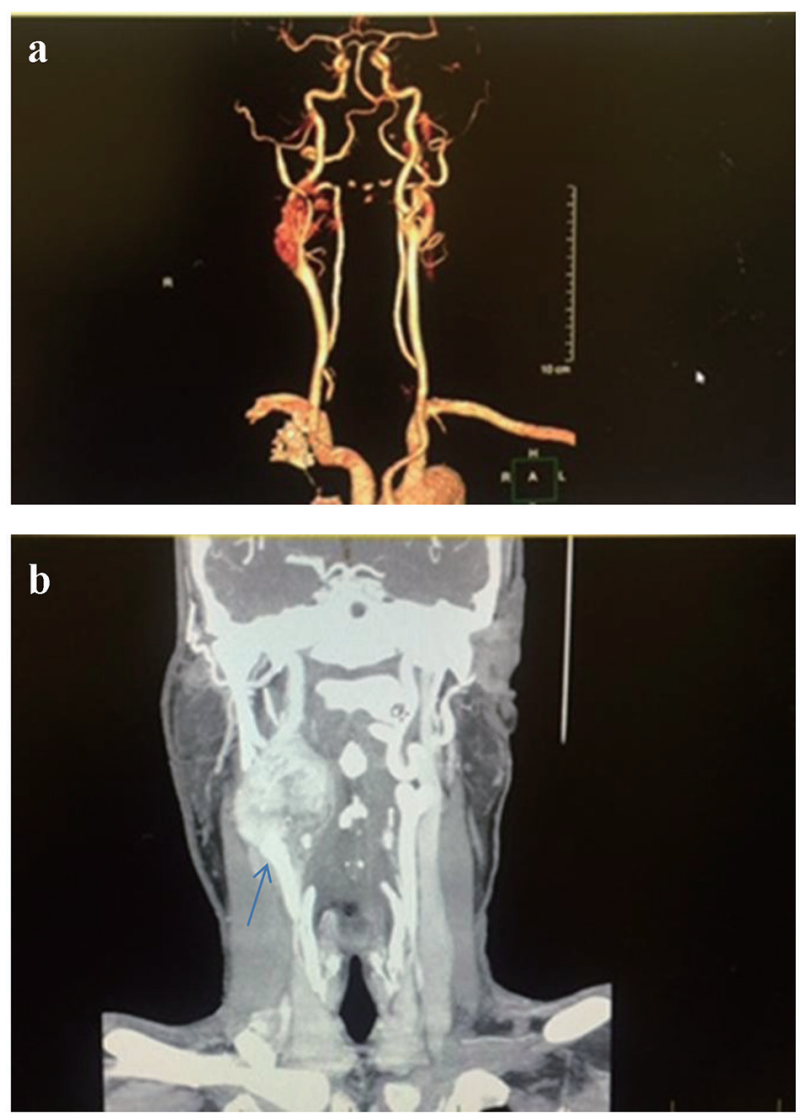

Figure 1. Computed tomography angiography (CTA) of the neck, coronal section, shows $4.9 \times 3.4 \times 4.5 \mathrm{~cm}$ enhancing mass at the carotid artery bifurcation (a) with mass effect on the right internal jugular vein and right airway (b). The carotid arteries are displaced as well.

vascular channels. The oval cells in the tumor formed nests (Zellballen structure) (Fig. 4). These cells were positive for neuroendocrine markers, synaptophysin and CD58 and negative for epithelial markers AE1/AE3. The whole picture was consistent with paraganglioma tumor with malignant behavior. The patient was referred to a tertiary oncology center for further management.

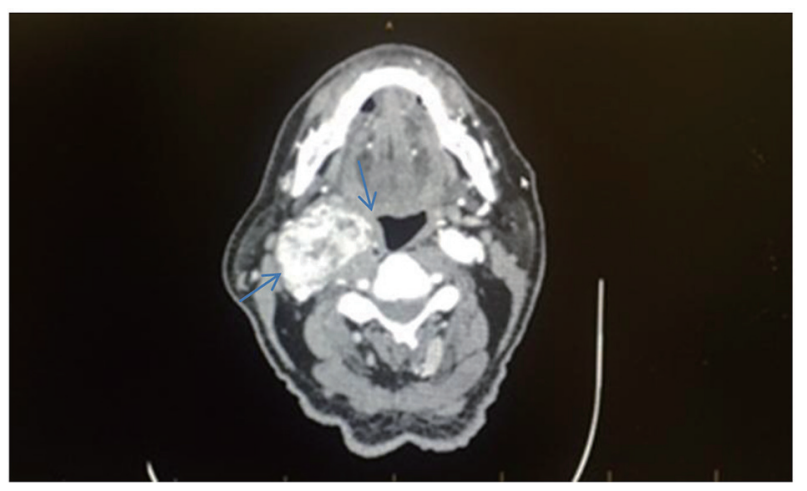

Figure 2. Computed tomography angiography (CTA) of the neck with and without contrast, axial section, shows an enhancing mass in the right side of the neck with mass effect on the right airway (blue arrows).

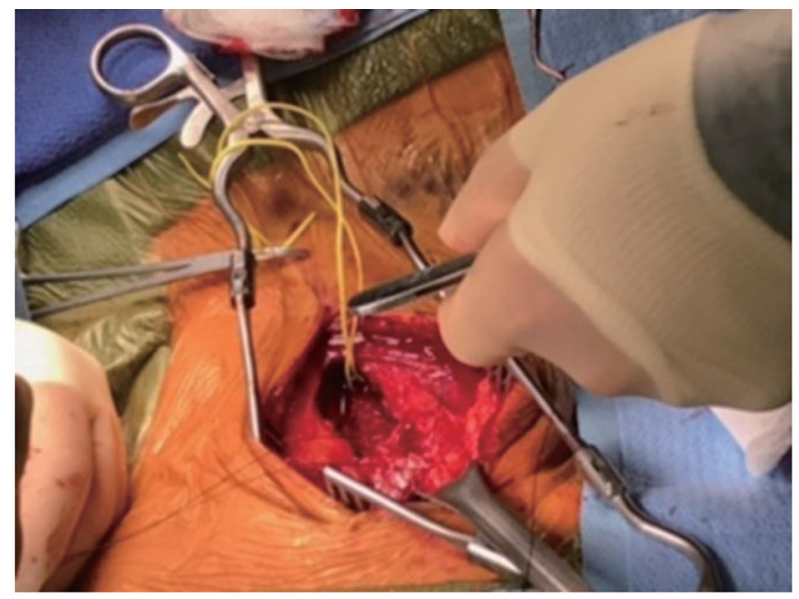

Figure 3. Perioperative finding of right side tumor that surrounds the carotid arteries.

\section{Discussion}

CBTs collectively known as paraganglioma tumors are very rare neoplasms that located at the bifurcation of the external and internal carotid arteries [4]. They are usually sporadic with few cases associated with familial/genetic syndromes [5]. The true incidence of these tumors remained largely unknown with some cases detected during autopsy examinations [6]. The original cells are derived from the neural crest during early embryonic development. Therefore, these tumors are related closely to other neural crest derived lesions like pheocromocytoma, and remained indistinguishable at the cellular level [7]. However, unlike other paragangilioma, CBTs are usually non-functional and may remain silent for years before clinical presentation similar to our case. Van Duinen et al and his colleagues conducted a prospective study where they found $23 \%$ of their patients with head and neck paragangilioma (31 out of 136) have biochemical active tumors [8]. It is therefore recommended to obtain biochemical and hormonal tests even if there were no signs of hormonal excess. Most patients present with a firm painless swelling in the lateral aspect of the neck. Owing to the crowded vascular and neural structures located in this area, no wonder, mass effect ensures at late stages. Patients may present with dysphagia, hoarseness of the voice or even Horner's syndrome secondary to compression of vagaus and/ or sympathetic nerves, respectively $[9,10]$. Airways pressure may occur in large size tumors as described in our patient.

Imaging modalities remain the gold standard in identifying and differentiating these tumors from other similar lesions sharing the same presentation. Carotid ultrasound is widely accepted as a first non-invasive tool to establish the diagnosis of CBTs. However, CT of neck angiography adds more detailed information, and reveals the relationship between lesions and adjacent arteries, as well as the involvement of the skull base [11]. In other words, it helps assess the tumor size and surgical (Shamblin) type more accurately (Fig. 5). In our case, the Doppler ultrasound had a major role in recognizing the CBT and eliminated other differentials like lymphoma, brachial cyst, thyroid mass and carotid aneurysm. CT angiography con- 

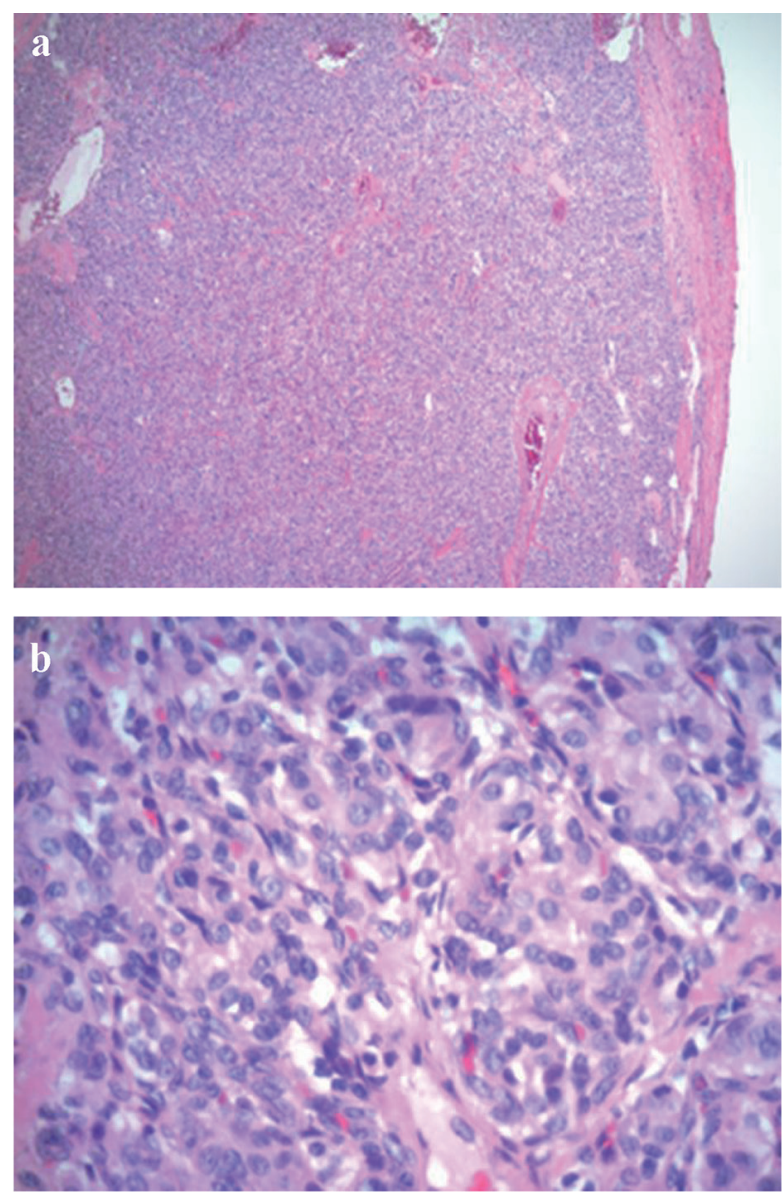

Figure 4. Low power $(\mathrm{a}: \times 4)$ and high power light microscopy $(\mathrm{b}: \times$ 40) showing oval cells arranged in compact cell nests (the so-called Zellballen appearance).

firmed the diagnosis and optimized the surgical plan approach. Moreover, CT imaging can help localize local and distant metastases, although very rare but have dismal prognosis once diagnosed [12].

Surgery remained the preferred management especially for localized and/or symptomatic tumors in otherwise healthy and fit patients. Less invasive approaches such as radiotherapy (RT) can be offered if surgical intervention deemed risky and has detrimental outcome $[13,14]$. This approach helps slow down the tumor growth and provides comfort care in symptomatic patients. Nonetheless, RT does not offer the same degree of symptom relief that is accomplished with surgical resection. Some authors suggested watchful approach (wait and scan) for small asymptomatic tumors $(<3 \mathrm{~cm})$, given the slow growth rate and the benign nature of most of these lesions [15]. Other interventions such as tumor embolization and radiosurgery have been advocated with controversial results in literature [16-18]. A recent retrospective study investigated the impact of embolization on outcome before CBT resection and no benefit was demonstrated with similar mortality, cranial nerve injury and blood loss [17], arguing against routine preoperative embolization approach.

Histologically, CBTs have distinct appearance described as

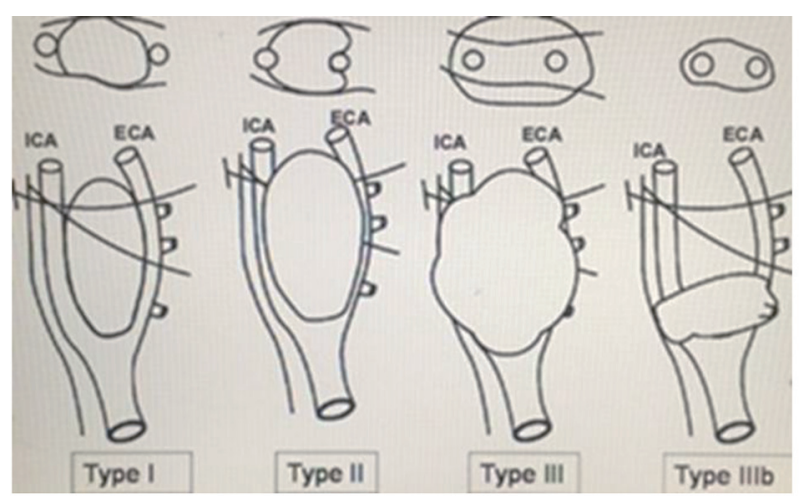

Figure 5. Schematic diagram of the Shamblin grouping of CBTs into I, II, III and IIlb. It is basically based on the relationship between the tumor and the carotid arteries. The intersected lines are the X and XII nerves which are closely related to the tumor. This diagram was adopted from Reference [18].

Zellballen appearance where round epithelioid cells arranged in dense cell nests or trabecular patterns (Fig. 4). However, this histological appearance is not pathognomonic and shared by variety of tumors. Immunohistochemical staining typically confirms the neuroendocrine nature of the cells which are positive for synaptophysin, chromogranin and/or neuron-specific enolase (NSE). In our patient, the tumor cells were positive for neuroendocrine markers synaptophysin and CD56, negative for epithelial markers AE1/AE3, and surrounded by S100 positive spindle cells (sustentacular cells). Nonetheless, malignant potential is difficult to predict based on histological findings and therefore, patients should be closely observed for any local or distant metastasis or recurrences [6].

\section{Conclusion}

CBTs remained rare neoplasms, often, non-secretory and may be overlooked till late stages and pressure effects with unfavorable outcomes. We believe, proper medical examination can help identify more of these tumors and hence, early and more aggressive approach can be applied before having malignant tendency and therefore poor prognosis.

\section{Conflict of Interest}

None.

\section{References}

1. Shamblin WR, ReMine WH, Sheps SG, Harrison EG, Jr. Carotid body tumor (chemodectoma). Clinicopathologic analysis of ninety cases. Am J Surg. 1971;122(6):732739.

2. Sutton MG, Sheps SG, Lie JT. Prevalence of clinically unsuspected pheochromocytoma. Review of a 50-year autopsy series. Mayo Clin Proc. 1981;56(6):354-360. 
3. Welander J, Soderkvist P, Gimm O. Genetics and clinical characteristics of hereditary pheochromocytomas and paragangliomas. Endocr Relat Cancer. 2011;18(6):R253276.

4. Davidovic LB, Djukic VB, Vasic DM, Sindjelic RP, Duvnjak SN. Diagnosis and treatment of carotid body paraganglioma: 21 years of experience at a clinical center of Serbia. World J Surg Oncol. 2005;3(1):10.

5. Drovdlic CM, Myers EN, Peters JA, Baysal BE, Brackmann DE, Slattery WH, 3rd, Rubinstein WS. Proportion of heritable paraganglioma cases and associated clinical characteristics. Laryngoscope. 2001;111(10):1822-1827.

6. McNeil AR, Blok BH, Koelmeyer TD, Burke MP, Hilton JM. Phaeochromocytomas discovered during coronial autopsies in Sydney, Melbourne and Auckland. Aust N Z J Med. 2000;30(6):648-652.

7. DeLellis RA, Lloyd RV, Heitz PU, Eng C, (Eds). Pathology and genetics of tumours of the endocrine organs. WHO Classification of Tumours. IARC press: Lyon, France; 2004.

8. van Duinen N, Steenvoorden D, Kema IP, Jansen JC, Vriends AH, Bayley JP, Smit JW, et al. Increased urinary excretion of 3-methoxytyramine in patients with head and neck paragangliomas. J Clin Endocrinol Metab. 2010;95(1):209-214.

9. Patetsios P, Gable DR, Garrett WV, Lamont JP, Kuhn JA, Shutze WP, Kourlis H, et al. Management of carotid body paragangliomas and review of a 30-year experience. Ann Vasc Surg. 2002;16(3):331-338.

10. Ma D, Liu M, Yang H, Ma X, Zhang C. Diagnosis and surgical treatment of carotid body tumor: A report of 18 cases. J Cardiovasc Dis Res. 2010;1(3):122-124.
11. Jin ZQ, He W, Wu DF, Lin MY, Jiang HT. Color doppler ultrasound in diagnosis and assessment of carotid body tumors: comparison with computed tomography angiography. Ultrasound Med Biol. 2016;42(9):2106-2113.

12. Kumari K, Jain D, Kumar R, Mohan A, Kumar R. Metastatic carotid body paraganglioma of lungs and lymph nodes: Unsuspected diagnosis on EBUS-TBNA. Diagn Cytopathol. 2017;45(4):327-332.

13. Huy PT, Kania R, Duet M, Dessard-Diana B, Mazeron JJ, Benhamed R. Evolving concepts in the management of jugular paraganglioma: a comparison of radiotherapy and surgery in 88 cases. Skull Base. 2009;19(1):83-91.

14. Hinerman RW, Amdur RJ, Morris CG, Kirwan J, Mendenhall WM. Definitive radiotherapy in the management of paragangliomas arising in the head and neck: a 35-year experience. Head Neck. 2008;30(11):1431-1438.

15. Zhang TH, Jiang WL, Li YL, Li B, Yamakawa T. Perioperative approach in the surgical management of carotid body tumors. Ann Vasc Surg. 2012;26(6):775-782.

16. Jansen JC, van den Berg R, Kuiper A, van der Mey AG, Zwinderman AH, Cornelisse CJ. Estimation of growth rate in patients with head and neck paragangliomas influences the treatment proposal. Cancer. 2000;88(12):28112816.

17. Cobb AN, Barkat A, Daungjaiboon W, Halandras P, Crisostomo P, Kuo PC, Aulivola B. Carotid body tumor resection: just as safe without preoperative embolization. Ann Vasc Surg. 2017.

18. Arya S, Rao V, Juvekar S, Dcruz AK. Carotid body tumors: objective criteria to predict the Shamblin group on MR imaging. AJNR Am J Neuroradiol. 2008;29(7):13491354. 